\title{
Quantitative evaluation of change in coexistent mitral regurgitation after aortic valve replacement
}

David J. Kaczorowski, MD, John W. MacArthur, MD, Jessica Howard, BS, Dale Kobrin, BS, Alex Fairman, BS, and Y. Joseph Woo, MD

Objectives: Management of intermediate degrees of mitral regurgitation during aortic valve replacement for aortic stenosis remains controversial. We sought to evaluate the degree of reduction of mitral regurgitation in patients undergoing aortic valve replacement, as well as a mathematical relationship between aortic valve gradient reduction and the degree of mitral regurgitation decrement.

Methods: We retrospectively analyzed demographic, intraoperative, and echocardiographic data on 802 patients who underwent aortic valve replacement or aortic root replacement between January 2010 and March 2011. A total of 578 patients underwent aortic valve replacement or aortic root replacement without intervention on the mitral valve. We excluded 88 patients with severe aortic insufficiency, 3 patients who underwent ventricular assist device placement, 4 patients who underwent prior mitral valve replacement, and 21 patients with incomplete data, yielding 462 patients for analysis. For each patient, the degree of pre- and postoperative mitral regurgitation was graded on a standard 0 to $4+$ scale.

Results: Of the 462 patients, 289 patients had at least mild mitral regurgitation. On average, mitral regurgitation decreased 0.24 degrees per patient for this cohort of 289 patients. Of the 56 patients with at least moderate mitral regurgitation, mitral regurgitation decreased 0.54 degrees per patient. Of 62 patients who underwent isolated aortic valve replacements, who had at least mild mitral regurgitation, and who had no evidence of structural mitral valve disease, mitral regurgitation decreased 0.24 degrees per patient. Linear regression analysis revealed no relationship between reduction in mitral regurgitation and gradient reduction across the aortic valve.

Conclusions: Reduction in mitral regurgitation after relief of aortic outflow tract obstruction is modest at best. Further, the magnitude of gradient change across the aortic valve has little influence on the degree of reduction in mitral regurgitation. These observations argue at minimum for performing a prospective evaluation of the clinical benefits of addressing moderate mitral regurgitation at the time of aortic valve intervention and may support a more aggressive approach to concomitant mitral surgery. (J Thorac Cardiovasc Surg 2013;145:341-8)

Coexistent mitral regurgitation (MR) is commonly encountered in the setting of aortic valve replacement (AVR) for aortic stenosis. ${ }^{1}$ Severe MR mandates surgical intervention at the time of AVR. Some evidence suggests that the presence of intermediate degrees of MR after AVR carries a worse prognosis. ${ }^{2-6}$ However, the mortality of doublevalve surgery may be substantially higher than that of isolated $\mathrm{AVR}^{7,8}$ Further, it is commonly thought that functional MR, when present in the setting of severe aortic

From the Division of Cardiovascular Surgery, University of Pennsylvania, Philadelphia, Pa.

Disclosures: Authors have nothing to disclose with regard to commercial support.

Read at the 38th Annual Meeting of The Western Thoracic Surgical Association,

Maui, Hawaii, June 27-30, 2012.

Received for publication June 23, 2012; revisions received Sept 15, 2012; accepted for publication Oct 22, 2012; available ahead of print Dec 13, 2012.

Address for reprints: Y. Joseph Woo, MD, Division of Cardiovascular Surgery, University of Pennsylvania, 3400 Spruce St, 6 Silverstein Pavilion, Philadelphia, PA 19104 (E-mail: joseph.woo@uphs.upenn.edu).

$0022-5223 / \$ 36.00$

Copyright (c) 2013 by The American Association for Thoracic Surgery

http://dx.doi.org/10.1016/j.jtcvs.2012.10.043 stenosis, improves significantly after AVR, which alleviates pressure overload. However, there is substantial disagreement in the literature over the proportion of patients who will experience improvement in MR after AVR, and the degree of improvement that can be expected is not well defined. ${ }^{1}$ For these reasons, the appropriate management of intermediate degrees of MR in the setting of AVR is undefined and remains controversial, with some authors advocating for a more aggressive surgical approach $^{2,3,5,8}$ and others advocating a more conservative approach. ${ }^{9,10}$ No randomized controlled clinical trials that address this issue have been published to date. Accordingly, after collating existing data in a systematic fashion, one group concluded that the evidence was inconclusive to make recommendations regarding surgical intervention on the mitral valve in the setting of moderate MR at the time of AVR. ${ }^{11}$ We sought to define the degree of improvement in MR that can be expected after AVR in a contemporary cohort of patients from a single center and to examine the relationship between change in MR and change in aortic pressure gradients after AVR. 


\section{Abbreviations and Acronyms \\ AVR = aortic valve replacement \\ $\mathrm{CABG}=$ coronary artery bypass grafting \\ $\mathrm{LV} \quad=$ left ventricular \\ MAC $=$ mitral annular calcification \\ MR = mitral regurgitation \\ $\mathrm{TAVR}=$ transcatheter aortic valve replacement}

\section{MATERIALS AND METHODS}

Demographic, intraoperative, and echocardiographic data on 802 patients who underwent intervention on the aortic valve (AVR or aortic root replacement) with or without intervention on the mitral valve (repair or replacement) between January 2010 and March 2011 were extracted from the Society of Thoracic Surgeons compliant database from the University of Pennsylvania. A total of 578 patients underwent AVR or aortic root replacement without intervention on the mitral valve. The decision to perform concomitant mitral valve surgical intervention at the time of AVR was made at the discretion of the operating surgeon. The presence of severe MR typically would prompt repair or replacement of the mitral valve at the time of AVR. Intervention on the mitral valve would be considered in the setting of intermediate degrees of MR in the presence of structural mitral valve disease. An individual patient's age and medical comorbidities would be considered in the ultimate decision as to whether to proceed with intervention on the mitral valve. We excluded 88 patients with severe aortic insufficiency, 3 patients who underwent ventricular assist device placement at the time of AVR, 4 patients who underwent prior mitral valve replacement, and 21 patients with incomplete data, yielding 462 patients for analysis.

\section{Grading of Mitral Regurgitation}

Data on MR for each patient were extracted from preoperative and postoperative echocardiograms. Routine intraoperative transesophageal echocardiography is used at the University of Pennsylvania, and the intraoperative completion transesophageal echocardiography was used as the postoperative echocardiogram in this study. Measurement of vena contracta width is the most commonly used method of classifying MR. MR was numerically graded as follows: none $=0$, trace $=0.5$, mild $=1$, moderate $=2$, moderate-severe $=3$, and severe $=4$. Intermediate degrees were assigned half of a degree. Change in the degree of MR for each patient was quantitated by subtracting the grade of preoperative MR from the degree of postoperative MR. Any patient with any abnormality of the mitral valve leaflets, the chordae tendineae, the papillary muscles, or the annulus (including mitral annular calcification [MAC] but excluding pure annular dilatation) was classified as having structural mitral valve disease. Patients with any degree of leaflet disease, including tethering, thickening, calcification, or prolapse, were considered to have a leaflet abnormality. To strictly identify patients with completely normal mitral valve architecture, even minor abnormalities (eg, small amounts of leaflet calcification) were considered abnormalities.

\section{Statistical Analysis}

Data were expressed as mean \pm standard deviation for continuous variables and as percentage for categoric variables. Categoric variables were compared using chi-square tests, and continuous variables were compared using $t$ tests or rank-sum tests. Simple linear regression was used to evaluate the relationship between change in MR and preoperative mean gradient across the aortic valve.

\section{RESULTS \\ Baseline Patient Characteristics and Operative Data}

Baseline characteristics and operative data of this cohort of 462 patients are presented in Tables 1 and 2. The patients in this cohort are predominantly elderly (average age, $72.9 \pm 10.9$ years), Caucasian $(90.9 \%)$, and male $(58.7 \%)$. A large fraction of the patients $(81.4 \%)$ have hypertension. A majority of these patients $(84.0 \%)$ had symptoms of heart failure preoperatively. New York Heart Association class 3 symptoms were observed in $37.4 \%$ of patients, and $10.0 \%$ of patients had class 4 symptoms. Diabetes $(29.4 \%)$, previous myocardial infarction (19.5\%), cerebrovascular disease $(19.9 \%)$, and peripheral arterial disease $(16.4 \%)$ also were observed in a substantial proportion of the patients. Five percent of the patients in this cohort require chronic hemodialysis.

Of the 462 patients in this cohort, a majority (59.3\%) underwent AVR only. However, $27.5 \%$ of patients underwent AVR and coronary artery bypass grafting (CABG), $1.9 \%$ of patients underwent AVR/CABG combined with another procedure (including left atrial appendage excision, Maze procedure, patent foramen ovale closure, septal myomectomy, and excision of cardiac tumor), and $8.0 \%$ of patients underwent AVR combined with another procedure (including ascending aortic aneurysm repair, septal myomectomy, aortic valve tumor resection, atrial septal defect repair, excision of left atrial myxoma, Maze procedure, patent foramen ovale closure, pacemaker removal, left atrial appendage excision, and pulmonary embolectomy). Aortic root replacement was performed in $1.7 \%$ of patients, and aortic root replacement combined with another procedure (including septal myomectomy, pulmonary artery patch, CABG) was performed in $1.5 \%$ of patients. Because patients with severe aortic insufficiency were excluded from this analysis, the predominant indication for AVR in these cases was aortic stenosis. This was the first cardiac surgery operation for most of the patients $(82.9 \%)$ in the cohort, but first $(15.6 \%)$, second $(1.3 \%)$, and third $(0.2 \%)$ reoperations also were performed in this series. Most of the cases in this series $(71.9 \%)$ were elective, but some $(26.4 \%)$ were considered urgent and few $(1.7 \%)$ were conducted on an emergency basis. Bioprosthetic aortic valves were used in the majority of cases $(93.3 \%)$. Mechanical valves were used less frequently $(6.1 \%)$, and homografts were rarely used $(0.4 \%)$. The average size of the valve implanted was $23.7 \pm 2.2 \mathrm{~mm}$.

\section{Fate of Mitral Regurgitation}

We next sought to determine the fate of coexistent MR after AVR. Overall trends in change in MR were examined by plotting the grade of preoperative and postoperative MR for individual patients. As an example, a plot demonstrating changes in MR after AVR for patients who underwent AVR only (no other concomitant procedure) 
TABLE 1. Baseline patient characteristics

\begin{tabular}{lc}
\hline Age $(\mathrm{y})$ & $72.9 \pm 10.9$ \\
Sex & \\
$\quad$ Male & $58.7 \%(\mathrm{n}=271)$ \\
$\quad$ Female & $41.3 \%(\mathrm{n}=191)$ \\
Race & \\
$\quad$ Caucasian & $90.9 \%(\mathrm{n}=420)$ \\
$\quad$ African American & $5.0 \%(\mathrm{n}=23)$ \\
Asian & $0.6 \%(\mathrm{n}=3)$ \\
Hispanic & $0.4 \%(\mathrm{n}=2)$ \\
Other/unspecified & $3.0 \%(\mathrm{n}=14)$ \\
Diabetes & $29.4 \%(\mathrm{n}=135)$ \\
Hypertension & $81.4 \%(\mathrm{n}=376)$ \\
Previous MI & $19.5 \%(\mathrm{n}=90)$ \\
Heart failure & $84.0 \%(\mathrm{n}=388)$ \\
NYHA class & \\
1 & $2.6 \%(\mathrm{n}=12)$ \\
2 & $34.0 \%(\mathrm{n}=157)$ \\
3 & $37.4 \%(\mathrm{n}=173)$ \\
4 & $10.0 \%(\mathrm{n}=46)$ \\
Cerebrovascular disease & $19.9 \%(\mathrm{n}=92)$ \\
Peripheral arterial disease & $16.4 \%(\mathrm{n}=76)$ \\
Dialysis & $5.0 \%(\mathrm{n}=23)$ \\
Creatinine & $1.11 \pm 0.893$ \\
Ejection fraction $(\mathrm{n}=454)$ & $56.4 \% \pm 12.8 \%$ \\
Mean aortic valve gradient $(\mathrm{mm} \mathrm{Hg}, \mathrm{n}=434)$ & $44.6 \pm 15.9$ \\
Mean pulmonary artery pressure $(\mathrm{mm} \mathrm{Hg}, \mathrm{n}=290)$ & $26.5 \pm 9.873$ \\
\hline
\end{tabular}

MI, Myocardial infarction; NYHA, New York Heart Association.

who had at least mild MR is illustrated in Figure 1. As Figure 1 shows, there is substantial variability in the change in MR after AVR without a clear trend toward

\section{TABLE 2. Operative data}

\begin{tabular}{lc}
\hline Nature of operation & \\
AVR & $59.3 \%(\mathrm{n}=274)$ \\
AVR + CABG & $27.5 \%(\mathrm{n}=127)$ \\
AVR + CABG + other & $1.9 \%(\mathrm{n}=9)$ \\
AVR + other & $8.0 \%(\mathrm{n}=37)$ \\
Aortic root replacement & $1.7 \%(\mathrm{n}=8)$ \\
Aortic root replacement + other & $1.5 \%(\mathrm{n}=7)$ \\
Incidence & \\
First cardiac surgery operation & $82.9 \%(\mathrm{n}=383)$ \\
First reoperation & $15.6 \%(\mathrm{n}=72)$ \\
Second reoperation & $1.3 \%(\mathrm{n}=6)$ \\
Third reoperation & $0.2 \%(\mathrm{n}=1)$ \\
Urgency & \\
Elective & $71.9 \%(\mathrm{n}=332)$ \\
Urgent & $26.4 \%(\mathrm{n}=122)$ \\
Emergency & $1.7 \%(\mathrm{n}=8)$ \\
Cardiopulmonary bypass time (min) & $119 \pm 49.6$ \\
Crossclamp time (min) & $85.8 \pm 39.1$ \\
Valve type & \\
Bioprosthesis & $93.3 \%(\mathrm{n}=432)$ \\
Mechanical & $6.1 \%(\mathrm{n}=28)$ \\
Homograft & $0.4 \%(\mathrm{n}=2)$ \\
Implant size (mm) & $23.7 \pm 2.2$ \\
\hline AVR Aotic valve
\end{tabular}

$A V R$, Aortic valve replacement; $C A B G$, coronary artery bypass grafting.

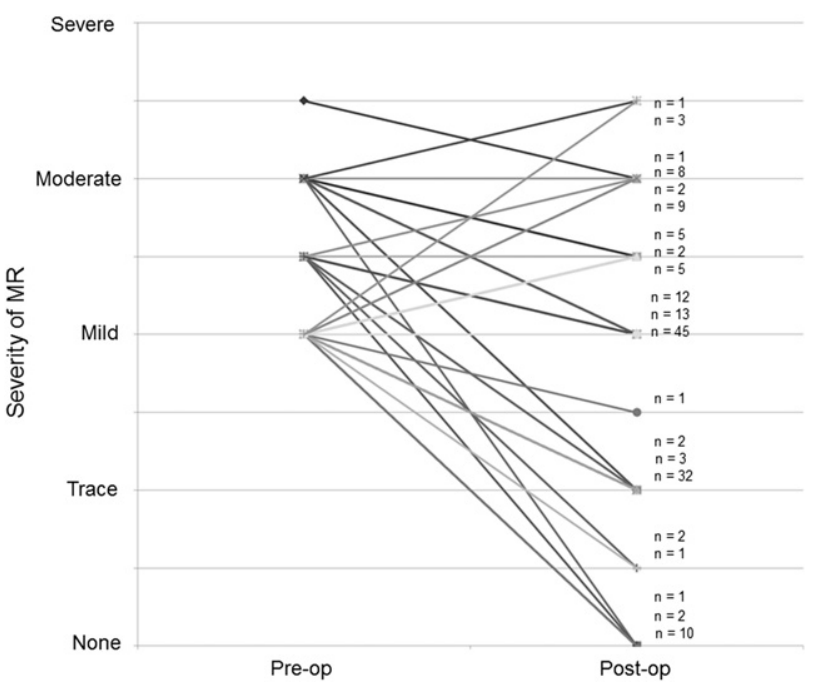

FIGURE 1. Trend plot of MR for patients undergoing AVR. The preoperative and postoperative grades of MR for individual patients undergoing AVR alone (without any concomitant procedure) who had at least mild preoperative MR were plotted. Because there is substantial overlap of individual plots, $\mathrm{n}$ values are used to indicate the number of patients represented by each line. $M R$, Mitral regurgitation.

improvement. Plots of other subgroups of patients yielded similar results.

\section{Quantitative Change in Mitral Regurgitation}

To quantify the change in MR that occurred in subgroups of patients in this cohort, we next used our numeric scoring system to evaluate the net change in MR in each group and on average per patient (Tables 3 and 4). The change in MR per patient was -0.11 degrees in patients with any preoperative MR, -0.24 degrees per patient in patients with at least mild MR, and -0.54 degrees in patients with at least moderate MR. Patients who underwent isolated AVR and had at least mild preoperative MR had downgrading of -0.28 degrees per patient. For patients who underwent isolated AVR, had at least mild preoperative MR, and had no mitral leaflet or chordal disease, the average change in MR was -0.26 degrees per patient. For patients who underwent isolated AVR, had at least mild preoperative MR, and had no disease of the mitral apparatus (including MAC), the average change in MR was -0.24 degrees per patient.

TABLE 3. Quantitative change in mitral regurgitation in patients undergoing aortic valve intervention

\begin{tabular}{lc}
\hline & $\begin{array}{c}\text { Change in MR per } \\
\text { patient }\end{array}$ \\
\hline Patients with MR $(\mathrm{n}=399)$ & -0.11 per patient \\
Patients with at least mild MR $(\mathrm{n}=289)$ & -0.24 per patient \\
Patients with at least moderate MR $(\mathrm{n}=56)$ & -0.54 per patient \\
\hline
\end{tabular}


TABLE 4. Quantitative change in mitral regurgitation in patients undergoing isolated aortic valve replacement

\begin{tabular}{lc}
\hline & $\begin{array}{c}\text { Change in MR per } \\
\text { patient }\end{array}$ \\
\hline AVR only with at least mild MR $(\mathrm{n}=169)$ & -0.28 per patient \\
AVR only, mild MR, no leaflet disease $(\mathrm{n}=135)$ & -0.26 per patient \\
AVR only, mild MR, no Mitral disease $(\mathrm{n}=62)$ & -0.24 per patient \\
\hline$M R$, Mitral regurgitation; $A V R$, aortic valve replacement. &
\end{tabular}

\section{Change in Mitral Regurgitation and Preoperative} Aortic Valve Gradient

To evaluate whether the change in MR observed after relief of aortic outflow tract obstruction is dependent on the preoperative gradient across the aortic valve and presumably the extent of pressure overload reduction with AVR, we next performed simple linear regression analysis. The change in MR for each patient after aortic valve intervention was plotted as a function of preoperative mean gradient across the aortic valve. When this analysis was performed for the entire cohort of 462 patients (Figure 2, A), no clear relationship between change in $\mathrm{MR}$ and preoperative mean gradient across the aortic valve was observed $\left(R^{2}=0.0002\right)$. To evaluate whether the net change in gradient across the aortic valve after AVR might influence the degree of improvement in MR, we also obtained data on the mean postoperative gradient across the aortic valve where available $(\mathrm{n}=335)$. The change in gradient across the aortic valve was calculated by subtracting the mean preoperative gradient from the mean postoperative gradient. The change in MR for each patient after aortic valve intervention was then plotted as a function of change in mean gradient across the aortic valve, and linear regression analysis was performed (Figure 2, B). No clear relationship between change in MR and change in mean gradient across the aortic valve was observed $\left(R^{2}=0.0002\right)$.

\section{Predictors of Improvement of Mitral Regurgitation}

Although the overall change in MR observed after relief of aortic outflow tract obstruction was modest, some patients did have some degree of improvement in MR, whereas others did not. To help identify factors that might predict improvement in MR, patients who underwent aortic valve intervention with mild or greater MR preoperatively were evaluated for improvement in MR. Patients were divided into groups depending on whether there was improvement in MR $(\mathrm{n}=137)$ or no improvement in MR $(\mathrm{n}=150)$. Preoperative and operative characteristics were compared (Tables 5 and 6). In the group of patients who did not experience improvement in MR, a greater proportion of patients had mild MR, whereas a greater proportion of patients in the group that did experience improvement had greater than mild degrees of MR. There were no significant differences in other preoperative or operative characteristics examined,
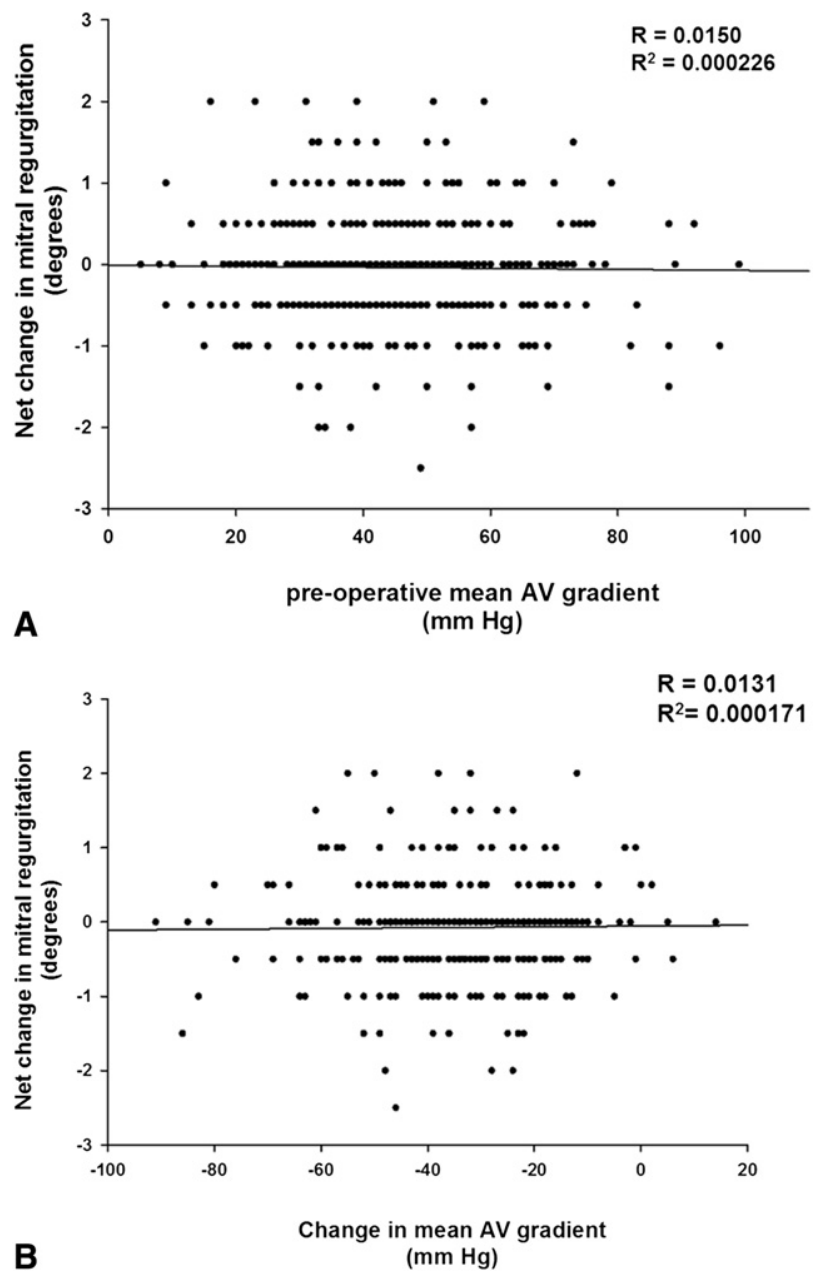

FIGURE 2. Change in MR as a function of the gradient across the aortic valve. A, Simple linear regression analysis of the change in MR for each patient according to the preoperative mean gradient across the aortic valve was performed for the entire cohort of 462 patients. B, Simple linear regression analysis of the change in MR for each patient according to the net change in mean gradient across the aortic valve was performed. $A V$, Aortic valve.

including ejection fraction, mean aortic valve gradient, mean pulmonary artery pressure, and left atrial diameter.

\section{DISCUSSION}

Previous studies have shown significant variability in the degree of improvement in MR after AVR. ${ }^{1}$ The most prominent finding of our study is that there is little improvement in MR after relief of aortic outflow tract obstruction by AVR. In the entire cohort of 462 patients who were analyzed, there was a decrease of only 0.08 degrees of MR per patient. Because this group contains patients with no $\mathrm{MR}$, it is not surprising that there was little net change in MR for the group. However, when the same analysis was performed for patients with MR $(\mathrm{n}=399)$ and patients with at least mild MR $(n=289)$, we found that the change 
TABLE 5. Comparison of baseline characteristics of patients with improvement in mitral regurgitation after aortic valve intervention versus those with no improvement

\begin{tabular}{|c|c|c|c|}
\hline & Improved $(n=137)$ & No improvement $(n=150)$ & $P$ value \\
\hline Age $(y)$ & $74.7 \pm 9.5$ & $74.5 \pm 9.9$ & $P=\mathrm{NS}$ \\
\hline \multicolumn{4}{|l|}{ Sex } \\
\hline Male & $54.7 \%(\mathrm{n}=75)$ & $56.7 \%(\mathrm{n}=85)$ & \multirow[t]{2}{*}{$P=\mathrm{NS}$} \\
\hline Female & $45.3 \%(n=62)$ & $43.3 \%(n=65)$ & \\
\hline \multicolumn{4}{|l|}{ Race } \\
\hline Caucasian & $90.5 \%(\mathrm{n}=124)$ & $91.3 \%(n=137)$ & \multirow[t]{5}{*}{$P=\mathrm{NS}$} \\
\hline African American & $8.0 \%(\mathrm{n}=11)$ & $4.7 \%(n=7)$ & \\
\hline Asian & $0.0 \%(n=0)$ & $1.3 \%(n=2)$ & \\
\hline Hispanic & $0.0 \%(\mathrm{n}=0)$ & $1.3 \%(n=2)$ & \\
\hline Other/unspecified & $1.5 \%(n=2)$ & $1.3 \%(n=2)$ & \\
\hline Atrial fibrillation/flutter & $24.1 \%(\mathrm{n}=33)$ & $28.7 \%(n=43)$ & $P=\mathrm{NS}$ \\
\hline Diabetes & $30.7 \%(n=42)$ & $28.0 \%(\mathrm{n}=42)$ & $P=\mathrm{NS}$ \\
\hline Hypertension & $81.0 \%(\mathrm{n}=111)$ & $81.3 \%(n=122)$ & $P=\mathrm{NS}$ \\
\hline Previous MI & $19.7 \%(\mathrm{n}=27)$ & $25.3 \%(\mathrm{n}=38)$ & $P=\mathrm{NS}$ \\
\hline Heart failure & $82.5 \%(n=113)$ & $90.0 \%(\mathrm{n}=135)$ & $P=\mathrm{NS}$ \\
\hline \multicolumn{4}{|l|}{ NYHA class } \\
\hline 1 & $1.5 \%(\mathrm{n}=2)$ & $1.3 \%(n=2)$ & \multirow[t]{4}{*}{$P=\mathrm{NS}$} \\
\hline 2 & $26.2 \%(n=36)$ & $32.7 \%(n=49)$ & \\
\hline 3 & $43.0 \%(\mathrm{n}=59)$ & $42.7 \%(n=64)$ & \\
\hline 4 & $10.2 \%(n=14)$ & $13.3 \%(n=20)$ & \\
\hline Cerebrovascular disease & $19.9 \%(n=26)$ & $20.7 \%(\mathrm{n}=31)$ & $P=\mathrm{NS}$ \\
\hline Peripheral arterial disease & $19.0 \%(\mathrm{n}=22)$ & $19.3 \%(\mathrm{n}=29)$ & $P=\mathrm{NS}$ \\
\hline Dialysis & $2.2 \%(\mathrm{n}=3)$ & $2.0 \%(\mathrm{n}=3)$ & $P=\mathrm{NS}$ \\
\hline Creatinine & $1.19 \pm 0.972$ & $1.12 \pm 0.769$ & $P=\mathrm{NS}$ \\
\hline Ejection fraction $(\%)$ & $54.0 \% \pm 13.9 \%(\mathrm{n}=135)$ & $56.0 \%+13.6 \%(\mathrm{n}=147)$ & $P=\mathrm{NS}$ \\
\hline Mean aortic valve gradient $(\mathrm{mm} \mathrm{Hg})$ & $45.4 \pm 16.0(\mathrm{n}=136)$ & $43.4 \pm 16.5(n=149)$ & $P=\mathrm{NS}$ \\
\hline Mean pulmonary artery pressure $(\mathrm{mm} \mathrm{Hg})$ & $27.2 \pm 9.7(\mathrm{n}=90)$ & $27.9 \pm 10.5(\mathrm{n}=94)$ & $P=\mathrm{NS}$ \\
\hline Left atrial diameter $(\mathrm{cm})$ & $4.46 \pm 0.85(\mathrm{n}=102)$ & $4.50 \pm 0.83(n=107)$ & $P=\mathrm{NS}$ \\
\hline \multicolumn{4}{|l|}{ Degree of preoperative MR } \\
\hline Mild & $49.6 \%(n=68)$ & $70.7 \%(\mathrm{n}=106)$ & \multirow[t]{5}{*}{$P=.003$} \\
\hline Mild-moderate & $25.5 \%(\mathrm{n}=35)$ & $14.7 \%(\mathrm{n}=22)$ & \\
\hline Moderate & $21.9 \%(\mathrm{n}=30)$ & $14.7 \%(n=22)$ & \\
\hline Moderate-severe & $2.2 \%(\mathrm{n}=3)$ & $0.0 \%(\mathrm{n}=0)$ & \\
\hline Severe & $0.7 \%(\mathrm{n}=1)$ & $0.0 \%(n=0)$ & \\
\hline Any structural MV disease & $69.3 \%(\mathrm{n}=95)$ & $63.3 \%(n=95)$ & $P=\mathrm{NS}$ \\
\hline MAC & $62.0 \%(\mathrm{n}=85)$ & $53.3 \%(\mathrm{n}=80)$ & $P=\mathrm{NS}$ \\
\hline Moderate or worse MAC & $24.1 \%(\mathrm{n}=33)$ & $30.0 \%(\mathrm{n}=45)$ & $P=\mathrm{NS}$ \\
\hline Leaflet abnormality & $23.4 \%(\mathrm{n}=32)$ & $21.3 \%(\mathrm{n}=32)$ & $P=\mathrm{NS}$ \\
\hline
\end{tabular}

$M I$, Myocardial infarction; $N Y H A$, New York Heart Association; $M V$, mitral valve; $M A C$, mitral annular calcification; $N S$, not significant.

in MR was less than a half of a degree per patient. However, when the same analysis was performed for patients with MR ( $\mathrm{n}=399)$ and patients with at least mild MR ( $\mathrm{n}=289$ ), we found that the change in MR was roughly a quarter of a degree per patient. Because some of these patients underwent concomitant $\mathrm{CABG}$ and some had evidence of intrinsic mitral valve disease (most commonly MAC), one could argue that these groups may include patients with some degree of ischemic MR or organic MR. However, when patients who had at least mild MR who underwent AVR only and had no evidence of any structural mitral valve disease (including MAC) were considered, there was still only a quarter of a degree of improvement in MR per patient after AVR. Thus, regardless of the scenario, one can expect on average approximately a quarter to a half of a degree reduction in MR at best with AVR for AS. This observation argues in favor of an aggressive approach of concomitant MV repair during AVR when preoperative MR is present.

Several studies have found that the degree of improvement in MR varies on the basis of cause. ${ }^{2,12}$ However, Unger and co-investigators ${ }^{13}$ found that the cause of MR was not predictive of improvement in MR. Our results support the finding by Unger and colleagues that the cause of MR does not predict reduction in MR. Specifically, there was no statistically significant difference in the proportion of patients who had leaflet abnormalities, MAC, or any structural MV disease between groups of patients who 
TABLE 6. Comparison of operative characteristics of patients with improvement in mitral regurgitation after aortic valve intervention versus those with no improvement

\begin{tabular}{|c|c|c|c|}
\hline & $\begin{array}{l}\text { Improved } \\
(\mathbf{n}=137)\end{array}$ & $\begin{array}{c}\text { No improvement } \\
(\mathbf{n}=\mathbf{1 5 0})\end{array}$ & \\
\hline Nature of operation & & & $P=\mathrm{NS}$ \\
\hline AVR & $64.2 \%(\mathrm{n}=88)$ & $54.0 \%(\mathrm{n}=81)$ & \\
\hline $\mathrm{AVR}+\mathrm{CABG}$ & $21.9 \%(\mathrm{n}=30)$ & $32.0 \%(\mathrm{n}=48)$ & \\
\hline $\mathrm{AVR}+\mathrm{CABG}+$ other & $2.2 \%(\mathrm{n}=3)$ & $2.7 \%(n=4)$ & \\
\hline AVR + other & $10.2 \%(n=14)$ & $7.3 \%(\mathrm{n}=11)$ & \\
\hline Aortic root replacement & $0.7 \%(\mathrm{n}=1)$ & $0.7 \%(n=1)$ & \\
\hline $\begin{array}{l}\text { Aortic root } \\
\text { replacement }+ \text { other }\end{array}$ & $0.7 \%(\mathrm{n}=1)$ & $3.3 \%(\mathrm{n}=5)$ & \\
\hline Incidence & & & $P=\mathrm{NS}$ \\
\hline $\begin{array}{l}\text { First cardiac surgery } \\
\text { operation }\end{array}$ & $81.0 \%(\mathrm{n}=111)$ & $81.3 \%(\mathrm{n}=122)$ & \\
\hline First reoperation & $17.9 \%(\mathrm{n}=24)$ & $17.3 \%(n=26)$ & \\
\hline Second reoperation & $1.5 \%(\mathrm{n}=2)$ & $1.3 \%(\mathrm{n}=2)$ & \\
\hline Third reoperation & $0.0 \%(\mathrm{n}=0)$ & $0.0 \%(\mathrm{n}=0)$ & \\
\hline Urgency & & & $P=\mathrm{NS}$ \\
\hline Elective & $70.1 \%(\mathrm{n}=96)$ & $70.7 \%(\mathrm{n}=106)$ & \\
\hline Urgent & $27.0 \%(\mathrm{n}=37)$ & $27.3 \%(n=41)$ & \\
\hline Emergency & $2.9 \%(n=4)$ & $2.0 \%(\mathrm{n}=3)$ & \\
\hline $\begin{array}{l}\text { Cardiopulmonary bypass } \\
\text { time (min) }\end{array}$ & $113 \pm 42.6$ & $125 \pm 53.9$ & $P=\mathrm{NS}$ \\
\hline Valve type & & & $P=\mathrm{NS}$ \\
\hline Bioprosthesis & $96.3 \%(\mathrm{n}=132)$ & $95.3 \%(\mathrm{n}=143)$ & \\
\hline Mechanical & $3.6 \%(\mathrm{n}=5)$ & $4.7 \%(\mathrm{n}=7)$ & \\
\hline Homograft & $0.0 \%(\mathrm{n}=0)$ & $0.0 \%(\mathrm{n}=0)$ & \\
\hline Implant size $(\mathrm{mm})$ & $23.8 \pm 2.1$ & $23.5 \pm 2.2$ & $P=\mathrm{NS}$ \\
\hline
\end{tabular}

$A V R$, Aortic valve replacement; $C A B G$, coronary artery bypass grafting; $N S$, not significant.

experienced improvement in MR compared with those who did not.

Aside from the cause of MR, a number of studies have identified preoperative parameters that seem to predict improvement in MR after AVR. Parameters identified include presence of coronary artery disease, absence of diabetes, absence of pulmonary hypertension, left atrial diameter less than $4.5 \mathrm{~cm}$, presence of congestive heart failure, lesser degrees of tricuspid regurgitation, absence of cerebrovascular disease, and lower left ventricular (LV) ejection fraction. ${ }^{4,14,15}$ Substantial variability exists in these findings and is likely attributable to differences in patient populations included in these studies, as well as variability in factors examined and quantitation of these variables. Our analysis was unable to confirm any of these variables as predictors of improvement in MR after AVR. One possibility is that the presence of functional MR after AVR is a symptom of advanced underlying LV pathology. For this reason, echocardiographic parameters of LV dysfunction, particularly diastolic dysfunction, may serve as better predictors of change in MR after AVR.

Preoperative MR severity was found to be a predictor of improvement in our study and others. ${ }^{14,15}$ Although more severe degrees of MR predict improvement, more than $40 \%$ of patients with moderate MR did not improve in our analysis. Furthermore, the degree of improvement in MR was modest. Specifically, only 0.56 degrees of improvement in MR was observed in the subgroup of patients who derived the greatest benefit. We found that improvement in MR is difficult to predict on the basis of simple preoperative characteristics.

The use of transcatheter aortic valve replacement (TAVR) is becoming an important method of addressing aortic stenosis in high-risk patients. Our observation that there is only modest improvement in MR after relief of aortic outflow tract obstruction through open aortic valve or aortic root replacement suggests that similar results would be observed after TAVR. A recent study aimed at addressing changes in MR after TAVR concurs with our observations. ${ }^{16}$ These results, in conjunction with our findings, suggest that one can expect minimal reduction in MR after TAVR.

\section{Study Limitations}

The major limitation of this study is the retrospective nature of the analysis. In addition, because LV remodeling may occur over time after AVR, MR may subsequently change over a longer period of time. One limitation of the current study is the lack of long-term echocardiographic data on patients. Of note, however, no changes were noted in postprocedural MR, compared with early or late follow-up in one study in which these parameters were examined. ${ }^{12}$ Another limitation of the use of intraoperative echocardiography is that both cardioplegic arrest and loading conditions may alter the degree of MR. For these reasons, both short- and long-term postoperative assessment of the degree of residual MR should be included in future prospective studies. In addition, quantitative volumetric measurements of the degree of MR also should be used in such studies.

\section{CONCLUSIONS}

Repairing severe MR in virtually every scenario yields significant benefit. ${ }^{17-22}$ Not treating intermediate levels of MR in certain settings such as ischemic heart disease portends a worse prognosis. ${ }^{23-25} \mathrm{MR}$ in the setting of aortic stenosis has not been as extensively studied, in part because intermediate MR may decrease with relief of LV pressure overload from AVR. Thus, the optimal management of intermediate degrees of MR at the time of AVR is undefined. Our data demonstrate that there is little improvement in MR after AVR for aortic stenosis. Furthermore, the degree of improvement in MR does not depend on the preoperative gradient across the aortic valve, nor does the extent of MR reduction correlate with extent of LV pressure gradient reduction. Our results indicate that it is difficult to predict which patients will experience any improvement in MR after 
AVR. Thus, our findings argue in favor of a more aggressive approach to moderate MR at the time of aortic valve intervention.

\section{References}

1. Unger P, Dedobbeleer C, Van Camp G, Plein D, Cosyns B, Lancellotti P. Mitral regurgitation in patients with aortic stenosis undergoing valve replacement. Heart. 2010;96:9-14.

2. Barreiro CJ, Patel ND, Fitton TP, Williams JA, Bonde PN, Chan V, et al. Aortic valve replacement and concomitant mitral valve regurgitation in the elderly: impact on survival and functional outcome. Circulation. 2005;112(9 Suppl): I443-7.

3. Moazami N, Diodato MD, Moon MR, Lawton JS, Pasque MK, Herren RL, et al. Does functional mitral regurgitation improve with isolated aortic valve replacement? J Card Surg. 2004;19:444-8.

4. Caballero-Borrego J, Gómez-Doblas JJ, Cabrera-Bueno F, García-Pinilla JM, Melero JM, Porras C, et al. Incidence, associated factors and evolution of non-severe functional mitral regurgitation in patients with severe aortic stenosis undergoing aortic valve replacement. Eur J Cardiothorac Surg. 2008;34:62-6.

5. Takeda K, Matsumiya G, Sakaguchi T, Miyagawa S, Yamauchi T, Shudo Y, et al. Impact of untreated mild-to-moderate mitral regurgitation at the time of isolated aortic valve replacement on late adverse outcomes. Eur J Cardiothorac Surg. 2010;37:1033-8.

6. Rankin JS, Hammill BG, Ferguson TB Jr, Glower DD, O'Brien SM, DeLong ER, et al. Determinants of operative mortality in valvular heart surgery. $J$ Thorac Cardiovasc Surg. 2006;131:547-57.

7. Litmathe J, Boeken U, Kurt M, Feindt P, Gams E. Predictive risk factors in double-valve replacement (AVR and MVR) compared to isolated aortic valve replacement. Thorac Cardiovasc Surg. 2006;54:459-63.

8. Harling L, Saso S, Jarral OA, Kourliouros A, Kidher E, Athanasiou T. Aortic valve replacement for aortic stenosis in patients with concomitant mitral regurgitation: should the mitral valve be dealt with? Eur J Cardiothorac Surg. 2011;40:1087-96.

9. Christenson JT, Jordan B, Bloch A, Schmuziger M. Should a regurgitant mitral valve be replaced simultaneously with a stenotic aortic valve? Tex Heart Inst J. 2000;27:350-5.

10. Absil B, Dagenais F, Mathieu P, Métras J, Perron J, Baillot R, et al. Does moderate mitral regurgitation impact early or mid-term clinical outcome in patients undergoing isolated aortic valve replacement for aortic stenosis? Eur J Cardiothorac Surg. 2003;24:217-22.

11. Alghamdi AA, Elmistekawy EM, Singh SK, Latter DA. Is concomitant surgery for moderate functional mitral regurgitation indicated during aortic valve replacement for aortic stenosis? A systematic review and evidence-based recommendations. J Card Surg. 2010;25:182-7.

12. Vanden Eynden F, Bouchard D, El-Hamamsy I, Butnaru A, Demers P, Carrier M, et al. Effect of aortic valve replacement for aortic stenosis on severity of mitral regurgitation. Ann Thorac Surg. 2007;83:1279-84.

13. Unger P, Plein D, Van Camp G, Cosyns B, Pasquet A, Henrard V, et al. Effects of valve replacement for aortic stenosis on mitral regurgitation. Am J Cardiol. 2008; 102:1378-82

14. Wan CK, Suri RM, Li Z, Orszulak TA, Daly RC, Schaff HV, et al. Management of moderate functional mitral regurgitation at the time of aortic valve replacement: is concomitant mitral valve repair necessary? J Thorac Cardiovasc Surg. 2009; 137:635-40.

15. Waisbren EC, Stevens LM, Avery EG, Picard MH, Vlahakes GJ, Agnihotri AK. Changes in mitral regurgitation after replacement of the stenotic aortic valve. Ann Thorac Surg. 2008;86:56-62.

16. Tzikas A, Piazza N, van Dalen BM, Schultz C, Geleijnse ML, van Geuns RJ, et al. Changes in mitral regurgitation after transcatheter aortic valve implantation. Catheter Cardiovasc Interv. 2010;75:43-9.

17. Suri RM, Aviernos JF, Dearani JA, Mahoney DW, Michelena HI, Schaff HV, et al. Management of less-than-severe mitral regurgitation: should guidelines recommend earlier surgical intervention? Eur J Cardiothorac Surg. 2011;40:496-502.

18. Suri RM, Schaff HV, Dearani JA, Sundt TM, Daly RC, Mullany CJ, et al. Recovery of left ventricular function after surgical correction of mitral regurgitation caused by leaflet prolapse. J Thorac Cardiovasc Surg. 2009;137:1071-6.

19. Stulak JM, Suri RM, Dearani JA, Burkhart HM, Sundt TM 3rd, EnriquezSarano M, et al. Does early surgical intervention improve left ventricular mass regression after mitral valve repair for leaflet prolapse? J Thorac Cardiovasc Surg. 2011;141:122-9.
20. Vaishnava P, Fuster V, Goldman M, Bonow RO. Surgery for asymptomatic degenerative aortic and mitral valve disease. Nat Rev Cardiol. 2011;8:173-7.

21. Carabello BA. The management of functional mitral regurgitation. Curr Cardiol Rep. 2007;9:112-7.

22. Schmitto JD, Lee LS, Mokashi SA, Bolman RM 3rd, Cohn LH, Chen FY. Functional mitral regurgitation. Cardiol Rev. 2010;18:285-91.

23. Grossi EA, Bizekis CS, LaPietra A, Derivaux CC, Galloway AC, Ribakove GH, et al. Late results of isolated mitral annuloplasty for "functional" ischemic mitral insufficiency. J Card Surg. 2001;16:328-32.

24. Kim YH, Czer LS, Soukiasian HJ, De Robertis M, Magliato KE, Blanche C, et al. Ischemic mitral regurgitation: revascularization alone versus revascularization and mitral valve repair. Ann Thorac Surg. 2005;79:1895-901.

25. Bax JJ, Braun J, Somer ST, Klautz R, Holman ER, Versteegh MI, et al. Restrictive annuloplasty and coronary revascularization in ischemic mitral regurgitation results in reverse left ventricular remodeling. Circulation. 2004;110(11 Suppl 1): II103-8

\section{Discussion}

Dr Gabriel Aldea (Seattle, Wash). This is an important and emerging topic, the incidence and significance of concomitant MR in the presence of aortic stenosis. I have 2 brief comments and several questions, and I will ask them sequentially.

The first comment is that you have shown these are coexistent conditions, and aortic stenosis and MR are common. In fact, $28 \%$ of your original 802 patients had a concomitant mitral valve surgery. That is a high incidence that supports a bias and institutional belief that many of us have that severe residual MR adversely affects survival and should be surgically addressed.

The second brief comment is, as you noted, we are dealing with significant multiple overlapping pathologies that are confounding, such as ischemic MR that can be seen in patients with CABG, which may be reversible, and you are trying to sort out functional MR from diseased mitral valve with primary pathology of the annulus, leaflet, and cords. These are difficult to sort out, but you managed to do this in your study by isolating patients with pure aortic stenosis and specifically those without other mitral valve pathology, and in those patients, the $56(12 \%)$ of the 462 with moderate or more MR, the magnitude of improvement when present was modest. This observation mirrors what we now know from the TAVR trials.

My first question is a methodological question. You have assessed the impact of AVR on residual MR in the operating room. I can see the logic and expediency of this, but what are the differences that you would expect with longer-term follow-up with serial echocardiographic studies without the impact of immediate postoperative changes and general anesthesia?

Dr Kaczorowski. In terms of longer-term follow-up, there are 2 studies in the literature that have looked at this retrospectively and on a smaller scale. When looking at patients at least 1 year out, according to an article published in The Annals of Thoracic Surgery in 2007 and a more recent article published in The Journal of Thoracic and Cardiovascular Surgery with a longer-term follow-up, significant changes were not observed in the proportion of patients who experienced improvement in MR. It is an important issue because there are 2 potential mechanisms that could be at work. One is immediate relief of the pressure gradient across the aortic valve. The second is longer-term remodeling that might occur with the left ventricle, which might result in improvement in the MR. These observations argue that the relief of the pressure gradient across the aortic valve is probably more important than 
the longer-term remodeling in terms of improvement in the MR. You alluded to some of the data that have been reported in the TAVR literature, and I think that is also what was seen in those reports. I am aware of 2 studies that looked at change in MR in the TAVR literature, and the immediate changes were not much different than the longer-term changes. In these studies, MR was measured immediately postoperatively and then approximately 1 month afterward, and the investigators found that there were no changes over that period of time. In the longer term, there is not as much change as you might expect from ventricular remodeling, and a good amount of the change is due to relief of that pressure gradient across the aortic valve.

Dr Aldea. The second question is a mechanistic question. You and others have noted that the presence of MR in a variety of situations, preceding and after CABG and now preceding AVR, has a significant negative impact on long-term survival. You have also shown that AV gradient does not correlate with the modest improvement in MR even if that is present. Given that, does the presence of nonstructural MR in the presence of symptomatic aortic stenosis reflect the advanced underlying pathology or chronicity or does it reflect other primary mitral valve issues? This is important because you might be looking at the wrong parameters. Parameters of diastolic dysfunction might correlate more than simply AV gradients. Ejection fraction and left atrial size may correlate better with impact or lack therefore of AVR on MR.

Dr Kaczorowski. It is difficult to know, but I think we can say, according to the mitral repair literature, that ongoing MR is certainly not a good thing. It leads to worse patient outcomes, and after mitral repair the persistence of MR has a detrimental effect on patients. Repairing the MR seems to improve patient outcomes. Data from studies on ischemic MR suggest that persistence of some intermediate degrees of MR portends a worse long-term prognosis. Whether repairing it makes a difference in that setting is more difficult to sort out, but again, from what we know in the literature, having ongoing long-standing MR is a bad thing. According to the mitral repair literature, repairing MR seems to mitigate some of those adverse effects of long-standing MR.

Dr Aldea. So let's talk about that, which leads to the third clinical question I have. Your conclusion suggests the more aggressive medical approach even for moderate MR, particularly when it is seen with concomitant aortic stenosis. This is a strong recommendation and to actually broaden your presentation from a mere analysis of intraoperative echocardiographic MR associated with AVR. You have an opportunity to sort that out because you can analyze the immediate risk, the mortality, and the perioperative mortality of the groups you have discussed (isolated AVR alone compared with concomitant AVR and MV surgery) and look at differences in survival over time. That is going to be particularly important because it may affect the choice of therapy that is offered to patients as we are looking at evolution of therapy choices for surgical AVR surgery, surgical sutureless AVR, and transcatheter aortic valve surgery, as well as percutaneous mitral valve approaches, particularly in elderly and sick patients (eg, surgical mitral valve repair, MitraClip with or without coronary sinus or device intervention). I am interested to see how your data answer the clinical relevance of residual MR in the presence of AS and how minimal impact of AVR on MR is going to change your group's management recommendation, as a leading group in TAVR nationally, in managing patients with aortic stenosis who present with MR.

Dr Kaczorowski. Certainly. I think that more data are required to answer that question. We do not have the mortality data that you are asking about. What I can tell you is that the persistence of MR portends a worse prognosis, and repairing it as we talked about may result in better patient outcomes. The approach to each of these patients has to be customized and dealt with on a per-patient basis. That is, in a high-risk patient we know that double-valve surgery carries greater operative risk. So patients who are at higher risk and perhaps less likely to benefit may not be candidates for a double-valve procedure, whereas younger healthier patients may be more appropriate candidates to pursue the MR in this setting.

Moderator. Okay, Richard, 1 question.

Richard Shemin (Los Angeles, Calif). Okay, how about a yes or no: Were these preoperative and postoperative measurements done under anesthesia in the operating room or what were the time points?

Dr Kaczorowski. I cannot give you a yes or no for that, but I can tell you the preoperative echocardiograms were done within 6 months of the procedure. The postoperative echocardiogram was done in the operating room. It was typically the immediate postoperative transesophageal echocardiogram.

Dr Shemin. So we know that has a significant error rate. How many of those patients actually went on to mitral valve repair or replacement in follow-up?

Dr Kaczorowski. I do not have those data for you.

Dr Shemin. Do you measure the left atrial size and the mitral valve annular size in your predictive model?

Dr Kaczorowski. We have the left atrial size, but I do not know if we have the annular dimensions.

Dr Shemin. See? One question, 3 parts. 